\title{
CAUSES OF CHILDHOOD BLINDNESS: RESULTS FROM WEST AFRICA, SOUTH INDIA AND CHILE
}

\author{
C. E. GILBERT ${ }^{1}$, R. CANOVAS ${ }^{2}$, M. HAGAN ${ }^{3}$, S. RAO ${ }^{4}$ and A. FOSTER ${ }^{1}$ \\ London; Concepción, Chile; Accra, Ghana; and Madurai, India
}

\begin{abstract}
SUMMARY
Using World Health Organization definitions of visual loss and a standardised methodology, 905 children were examined in Chile, West Africa and South India. Of these $806(89 \%)$ suffered from blindness (BL) or severe visual impairment (SVI). Causes of SVI and BL were classified anatomically and aetiologically, and avoidable causes identified. In W. Africa $(\boldsymbol{n}=\mathbf{2 8 4})$ the major anatomical cause of SVI/BL was corneal scar/phthisis bulbi (35.9\%). Retinal disease accounted for $20.4 \%$, cataract $15.5 \%$ and glaucoma $13.0 \%$. Aetiologically $33.8 \%$ of SVI/BL was due to childhood factors and $21.1 \%$ to hereditary disease. In S. India $(n=305)$ the major anatomical cause of SVI/BL was corneal scar/phthisis bulbi (38.4\%). Retinal disease accounted for $22.6 \%$, cataract $7.4 \%$ and glaucoma $3 \%$. Aetiologically $37.0 \%$ of SVI/BL was due to childhood factors and $29.8 \%$ to hereditary disease. In Chile $(n=217)$ the major anatomical cause of SVI/BL was retinal disease (47.0\%). Cataract accounted for $9.2 \%$, glaucoma $8.3 \%$ and $6.9 \%$ was due to corneal pathology. Aetiologically $30.4 \%$ of $\mathrm{SVI} / \mathrm{BL}$ was due to hereditary factors, and $20.8 \%$ to perinatal factors of which four-fifths $(\mathbf{1 6 . 6 \%})$ was due to retinopathy of prematurity. Avoidable conditions accounted for $70 \%, 47 \%$ and $54 \%$ of cases in $W$. Africa, S. India and Chile respectively.
\end{abstract}

Little data are available concerning the causes of childhood blindness from many parts of the world. This information is necessary for planning appropriate control measures. Standardised definitions, classification systems and methods of recording and analysing data are necessary in order to monitor changing patterns of childhood blindness over time in response to changes in socioeconomic development or specific interventions.

Blind school studies have previously been undertaken

From: 'Department of Preventive Ophthalmology, Institute of Ophthalmology, London; ${ }^{2}$ Corporacion de Ayuda al Limitado Visual, Concepción, Chile; ${ }^{3}$ Kole Bu Hospital, Accra, Ghana, West Africa; and ${ }^{4}$ Aravind Eye Hospital, Madurai, Tamil Nadu, South India.

Correspondence to: Miss C. E. Gilbert, MB, ChB, FRCS, FCOphth, Department of Preventive Ophthalmology, Institute of Ophthalmology, Bath Street, London EC1V 9EL, UK. in some Latin American and African countries, ${ }^{1-7}$ but no data are available from Chile or South India. The major causes of blindness vary from country to country and within a country over time, reflecting different levels of socioeconomic development and provision of health care services.' Data from one country cannot therefore be extrapolated to another.

Data that are available have used a variety of definitions and classification systems so that comparison of results is difficult to interpret. A standard reporting form for causes of blindness and low vision has been developed in collaboration with the World Health Organization's Prevention of Blindness Programme (WHO/PBL Eye Examination Record for Children with Blindness and Low Vision), ${ }^{8}$ in order to standardise the methodology for recording causes of visual loss in children. The form allows recording of information which can be used to:

1. Assess requirements of individual children for medical or surgical management, optical correction, or low vision therapy.

2. Identify the major preventable or treatable causes of visual loss so that appropriate control measures can be designed and implemented at a national level.

3. Monitor changing patterns of childhood blindness over time in response to changes in health care, specific interventions and socioeconomic development.

4. Assess educational needs of visually disabled children so that suitable education services can be planned.

The WHO/PBL form was used in the blind school studies reported in this paper.

\section{SUBJECTS AND METHODS}

A total of 905 pupils attending 16 schools for the blind were examined in Chile, West Africa (Ghana, Togo and Benin), and Tamil Nadu State in South India. This represents $62 \%$ and $60 \%$ of the blind school population of Chile and Tamil Nadu State respectively and 93\% of children attending schools for the blind in Ghana, Togo and Benin.

The age range was 3-28 years. Young adults who 
became blind before the age of 16 years were included in the study.

Visual acuity levels of $6 / 18,6 / 60$ and 3/60 were measured with an Illiterate $E$ chart by one observer in each blind school. Each eye was tested separately and then both eyes together, with correction if this was normally worn. If examination of the eyes indicated that visual acuity could be improved, testing was repeated with a pinhole. Levels of visual acuity were categorised according to the WHO definitions of visual loss (Table I).

Refraction was not performed routinely and visual fields were not tested. Anterior segment examination was performed with a torch and magnifying loupe, and/or portable slit lamp (Zeiss). Posterior segment examination was undertaken after dilating the pupil where indicated, using a direct and/or indirect ophthalmoscope. Intraocular pressures were not routinely measured. The majority of children were examined by one observer (C.E.G.). The remainder were examined by local ophthalmologists working with CEG during the same visit (R.C., M.H., S.R.).

Records giving details of past medical and ocular history were only available in Chile. In the other locations further information was obtained from the children, teachers at the school and occasionally from parents.

All data were recorded on the WHO/PBL Eye Examination Record for Children with Blindness and Low Vision. The form is accompanied by Coding Instructions, which give instructions for use, definitions and methods of classification. The form allows for recording causes of visual loss using a descriptive, anatomical classification, and an aetiological classification. The anatomical classification is useful for situations where details of past medical history are absent or scanty as the anatomical site of abnormality leading to visual loss can be determined by clinical examination.

The aetiological classification used employs the time of insult leading to visual loss. The Coding Instructions give definitions of each of the categories. After examining each child, the major anatomical site of abnormality leading to visual loss was determined for each eye, and for the child as an individual. If one eye had more than one structural abnormality, or if the abnormalities were different for the right and left eyes, the major abnormality for each eye and the child were selected using criteria given in the Coding Instructions, which place emphasis on the identification of preventable or treatable conditions. The aetiology of visual loss was also determined for each eye and for the child as an individual.

The results presented are for the anatomical and aeti-

Table I. WHO categories of visual loss ${ }^{\mathrm{a}}$

\begin{tabular}{ll}
\hline Normal vision & $6 / 18$ or better \\
Visual impairment & Less than $6 / 18$ to $6 / 60$ \\
Severe visual impairment & Less than $6 / 60$ to $3 / 60$ \\
Blind & Less than $3 / 60$ to NPL \\
Blind & Visual field $<10^{\circ}$ \\
\hline
\end{tabular}

${ }^{a}$ Corrected visual acuity of the better eye.

NPL, no perception of light. ological causes of severe visual impairment and blindness (SVI/BL) in each child.

\section{RESULTS}

\section{Visual Acuity}

Results of visual acuity measurement are shown in Table II, which gives categories of visual loss in the better eye, corrected with spectacles or pinhole. The majority of children in each location were blind or severely visually impaired (83.2-92.7\%); 7.3-16.8\% of children had visual impairment or normal vision.

\section{Anatomical Cause of Visual Loss}

Anatomical causes of blindness are given in Table III.

Corneal scarring/phthisis bulbi was the commonest cause of SVI/BL in West Africa (35.9\%) and South India $(38.4 \%)$.

Retinal blindness was the commonest anatomical cause of SVI/BL in Chile (47\%) and the second most common cause in West Africa and South India $(20.4 \%$ and $22.6 \%$ respectively). Retinal dystrophies accounted for $15.8 \%$ (45/284), $21.3 \%$ (65/305) and 18.4\% (40/217), and retinopathy of prematurity (ROP) 0,0 and $16.6 \%(36 / 217)$ respectively in West Africa, South India and Chile.

Both congenital cataract and glaucoma were relatively more important in West Africa (15.5\% and 13.0\%) than South India (7.4\% and 3.0\%) or Chile $(9.2 \%$ and $8.3 \%$ ).

Microphthalmos/anophthalmos was seen in $6.3 \%$ $(16+2 / 284), 16.7 \%(41+10 / 305)$ and $7.4 \%(11+5 / 217)$ in West Africa, South India and Chile respectively.

Optic nerve disease was responsible for 5.6-12\% and uveal disease $1.1-2.3 \%$ of SVI/BL in the three locations.

\section{Aetiological Category of Visual Loss}

The aetiologies of visual loss for each location are shown in Table IV. Visual loss was attributable to hereditary disease in $21.1-30.4 \%$ of children, with retinal dystrophies accounting for between $60 \%$ and $75 \%$ of the hereditary diseases in the three locations.

Congenitally acquired rubella (CAR) was the principal intrauterine factor causing SVI/BL: $6.7 \%$ (19/284), 0.7\% $(2 / 305)$ and $7.4 \%(16 / 217)$ in West Africa, South India and Chile.

ROP, resulting from events occurring during the perinatal period, accounted for $16.6 \%$ of childhood blindness in Chile, but was not seen in South India and West Africa. Analysis of data by age group in Chile (excluding those with childhood causes) shows that $27 / 107$ children aged

Table II. Results of visual acuity measurement of 905 children in blind schools in Chile, West Africa and South India, using WHO categories of visual loss

\begin{tabular}{lrrr}
\hline Category of visual loss & $\begin{array}{c}\text { Chile } \\
(n=261)\end{array}$ & $\begin{array}{c}\text { W. Africa } \\
(n=315)\end{array}$ & $\begin{array}{c}\text { S. India } \\
(n=329)\end{array}$ \\
\hline Normal vision & $6.1 \%$ & $1.9 \%$ & $1.5 \%$ \\
Visual impairment (VI) & $10.7 \%$ & $7.9 \%$ & $5.8 \%$ \\
Severe visual impairment (SVI) & $9.2 \%$ & $6.6 \%$ & $6.7 \%$ \\
Blind (BL) & $74.0 \%$ & $83.6 \%$ & $86.0 \%$ \\
\hline
\end{tabular}


Table III. Anatomical causes of blindness and severe visual impairment in children in West Africa, South India and Chile

\begin{tabular}{|c|c|c|c|c|c|c|}
\hline \multirow{2}{*}{ Category } & \multicolumn{2}{|c|}{ West Africa } & \multicolumn{2}{|c|}{ South India } & \multicolumn{2}{|c|}{ Chile } \\
\hline & $n$ & $\%$ & $n$ & $\%$ & $n$ & $\%$ \\
\hline Whole globe & 24 & 8.5 & 61 & 20.0 & 19 & 8.8 \\
\hline $\mathrm{CS} / \mathrm{PB}$ & 102 & 35.9 & 117 & 38.4 & 23 & 10.6 \\
\hline Lens & 44 & 15.5 & 23 & 7.4 & 20 & 9.2 \\
\hline Uvea & 3 & 1.1 & 6 & 2.0 & 5 & 2.3 \\
\hline Retina & 58 & 20.4 & 69 & 22.6 & 102 & 47.0 \\
\hline Optic nerve & 16 & 5.6 & 17 & 5.6 & 26 & 12.0 \\
\hline Glaucoma & 37 & 13.0 & 9 & 3.0 & 18 & 8.3 \\
\hline Normal globe & 0 & 0 & 3 & 1.0 & 4 & 1.8 \\
\hline Total & 284 & 100 & 305 & 100 & 217 & 100 \\
\hline
\end{tabular}

$\mathrm{CS} / \mathrm{PB}$, corneal scar/phthisis bulbi.

10 years and younger were blind from ROP compared with $9 / 84$ aged over 10 years $(p>0.005)$. Visual loss due to ophthalmia neonatorum was seen in 6 or 7 children in each location $(2-3 \%)$.

SVI/BL from events occurring during childhood was seen in $33.8 \%, 37.0 \%$ and $12 \%$ of children in West Africa, South India and Chile. Of these children, 94/113 in South India, 81/96 in West Africa and 2/26 in Chile were blind from corneal scarring and phthisis bulbi.

Congenital anomalies where it could not be determined whether the aetiology was due to hereditary or intrauterine factors, accounted for $25.7 \%$ (73/284), 25.2\% (77/305) and $17.5 \%(38 / 217)$ of cases in West Africa, South India and Chile.

\section{Avoidable Causes of Childhood Blindness}

Some conditions which lead to childhood blindness are preventable (i.e. are amenable to primary prevention), including CAR, vitamin A deficiency, measles and ophthalmia neonatorum. Other conditions, if diagnosed early, can be treated to prevent visual loss (i.e. are amenable to secondary prevention), including glaucoma, cataract, xerophthalmia and stage III 'plus' ROP. Sight can also be restored to some degree in children with congenital cataract or corneal scar (i.e. tertiary prevention). The term 'avoidable blindness' is used to encompass the conditions causing SVI/BL which can be prevented or treated.

Avoidable blindness was responsible for $70 \%, 47 \%$ and $54 \%$ of SVI/BL in West Africa, South India and Chile respectively. Corneal scarring was the major avoidable cause in West Africa and South India, and ROP in Chile (Table V).

Table IV. Aetiological category of visual loss for children in blind schools in West Africa, South India and Chile

\begin{tabular}{lrrrrrr}
\hline \multirow{2}{*}{ Category } & \multicolumn{2}{c}{ West } & Africa & \multicolumn{2}{c}{ South India } & \multicolumn{2}{c}{ Chile } \\
\cline { 2 - 7 } & \multicolumn{1}{c}{$n$} & \multicolumn{1}{c}{$\%$} & \multicolumn{1}{c}{$n$} & \multicolumn{1}{c}{$\%$} & \multicolumn{1}{c}{$n$} & $\%$ \\
\hline Hereditary & 60 & 21.1 & 91 & 29.8 & 66 & 30.4 \\
Intrauterine & 22 & 7.7 & 4 & 1.3 & 20 & 9.2 \\
Perinatal & 7 & 2.5 & 7 & 2.3 & 45 & 20.8 \\
Childhood & 96 & 33.8 & 113 & 37.0 & 26 & 12.0 \\
Unclassified & 99 & 34.9 & 90 & 29.6 & 60 & 27.6 \\
Total & 284 & 100 & 305 & 100 & 217 & 100 \\
\hline
\end{tabular}

\section{DISCUSSION}

It is estimated that there are 1.5 million blind children in the world, of which 65\% live in Asia and $20 \%$ in Africa. ${ }^{9}$ At least half and possibly up to three-quarters of childhood blindness is avoidable. ${ }^{10}$ In order to develop control programmes to prevent childhood blindess it is necessary to identify important avoidable causes in each country and to monitor the changing patterns of childhood SVI/BL in each country over time.

\section{Sources of Data on Childhood Blindness}

Possible sources of data on childhood blindness include blind registers, population-based surveys, and studies based in blind schools or hospitals. Difficulties arise in obtaining data from developing countries as blind registers are not kept and the majority of blind children not identified. To obtain accurate information on the causes of childhood blindness from population-based surveys a very large study would be required in order to obtain sufficient cases because of the low prevalence of childhood blindness, estimated to vary from 0.3 to 1.5 per 1,000 children. ${ }^{9}$ Hospital-based studies are unsatisfactory because of referral bias towards treatable conditions. Examination of children in blind schools has several limitations and disadvantages. Children in blind schools are not representative of the childhood blind population because:

Table V. Causes of avoidable childhood blindness in West Africa, South India and Chile

\begin{tabular}{|c|c|c|c|c|}
\hline Location & $\begin{array}{l}\text { Causes of avoidable } \\
\text { blindness }\end{array}$ & $n$ & Total & $(\%)$ \\
\hline $\begin{array}{l}\text { West Africa } \\
(n=284)\end{array}$ & $\begin{array}{l}\text { Preventable diseases } \\
\text { Corneal scarring/phthisis } \\
\text { bulbi from VAD/measles/ } \\
\text { TEM } \\
\text { Congenital rubella } \\
\text { Ophthalmia neonatorum } \\
\text { Aut. D hereditary disease } \\
\text { Treatable conditions } \\
\text { Glaucoma } \\
\text { Cataract } \\
\text { Others }\end{array}$ & $\begin{array}{r}81 \\
19 \\
7 \\
4 \\
\\
37 \\
28 \\
22\end{array}$ & $\begin{array}{r}29 \% \\
7 \% \\
2 \% \\
1 \% \\
\\
13 \% \\
10 \% \\
8 \%\end{array}$ & $39 \%$ \\
\hline $\begin{array}{l}\text { South India } \\
(n=305)\end{array}$ & $\begin{array}{l}\text { Preventable diseases } \\
\text { Corneal scarring/phthisis } \\
\text { bulbi from VAD/measles/ } \\
\text { TEM } \\
\text { Aut. D/X-L hereditary } \\
\text { disease } \\
\text { Ophthalmia neonatorum } \\
\text { Treatable conditions } \\
\text { Cataract } \\
\text { Glaucoma } \\
\text { Others }\end{array}$ & $\begin{array}{r}94 \\
14 \\
6 \\
19 \\
8 \\
2\end{array}$ & $\begin{array}{r}31 \% \\
4 \% \\
2 \% \\
6 \% \\
3 \% \\
1 \%\end{array}$ & $37 \%$ \\
\hline $\begin{array}{l}\text { Chile } \\
(n=217)\end{array}$ & $\begin{array}{l}\text { Preventable diseases } \\
\text { Aut. D/X-L hereditary } \\
\text { disease } \\
\text { Congenital rubella } \\
\text { Ophthalmia neonatorum } \\
\text { Treatable conditions } \\
\text { Retinopathy of prematurity } \\
\text { Cataract } \\
\text { Glaucoma } \\
\text { Others }\end{array}$ & $\begin{array}{r}18 \\
16 \\
6 \\
36 \\
16 \\
13 \\
13\end{array}$ & $\begin{array}{r}8 \% \\
7 \% \\
3 \% \\
\\
17 \% \\
7 \% \\
6 \% \\
6 \%\end{array}$ & $18 \%$ \\
\hline
\end{tabular}

Aut. D, autosomal dominant; TEM, traditional eye medicines; VAD, vitamin A deficiency; X-L, X-linked. 
1. Preschool children are under-represented.

2. Blind children with other handicaps may be denied admission.

3. The schools are often situated in cities and blind children from rural areas may not obtain admission for a variety of reasons.

4. Children with SVI but some residual vision may be integrated into normal schools.

5. School attendance rates are lower for girls than boys in many developing countries and this is also true of blind schools.

The major advantages of blind school studies are that a large number of children can be examined for the cause of blindness, which is not feasible in a population-based survey, and the children can be examined in a standard way by one or two examiners, allowing conformity in reporting, which is difficult to obtain with blind registers.

\section{Corneal Scar/Phthisis Bulbi}

In West Africa and South India the major avoidable cause of childhood blindness was corneal scarring/phthisis bulbi (Table V). Although it is difficult to ascertain definitely the aetiology of corneal scarring several years after the original pathology, available evidence from Africa suggests that the major cause is vitamin A deficiency, and the second cause the use of harmful traditional eye medicines. ${ }^{11}$ Measles is an important predisposing factor for both mechanisms. Ophthalmia neonatorum accounted for $2-3 \%$ of cases in each location in these studies.

Health and nutrition education together with measles immunisation and vitamin A supplementation offer the potential to prevent one-third of childhood blindness in West Africa and South India. In Chile, where vitamin A deficiency is not a public health problem and measles immunisation coverage more than 90\% (UNICEF 1990 Report), corneal scarring occurring during childhood accounted for only $1.4 \%$ of cases.

\section{Cataract and Glaucoma}

Congenital cataract and glaucoma are both surgically treatable conditions for which early diagnosis and treatment offers the possibility of reducing visual loss.
These conditions accounted for $28.5 \%(n=81), 10.4 \%$ $(n=32)$ and $17.5 \%(n=38)$ of childhood SVI/BL in West Africa, South India and Chile. The two commonest aetiological factors for both diseases are hereditary factors or CAR, the remainder being of undetermined aetiology. CAR accounted for $19(6.7 \%), 2(0.7 \%)$ and $16(7.4 \%)$ cases in the three respective locations, but this is almost certainly an under-estimate as laboratory investigations to identify cases were not performed.

\section{Retinal Disease}

Retinal disease accounted for 58 (20.4\%), 69 (22.6\%) and $102(47.0 \%)$ cases of childhood SVI/BL in West Africa, South India and Chile. Hereditary retinal dystrophies were responsible for $45(15.8 \%), 65(21.3 \%)$ and $40(18.7 \%)$ cases in the respective locations.

ROP was not seen in West Africa or South India but was responsible for 36 cases in Chile (16.6\%). The available data suggests that ROP is emerging as an important cause of childhood blindness in Chile, being responsible for $24.3 \%(27 / 111)$ of SVI/BL in children aged $0-10$ years. This is probably due to the increased survival of lowbirthweight and premature babies consequent upon improved neonatal care.

Monitoring of oxygen therapy in neonatal units may reduce the incidence of ROP. Screening of infants with a birthweight of less than $1.5 \mathrm{~kg}$ can identify those babies who have stage III 'plus' disease in whom cryotherapy is indicated to reduce the risk of progression to blinding disease. $^{12}$

\section{Hereditary Disease}

At least $20 \%$ of cases of SVI/BL in each location were due to hereditary disease. It is also likely that some of the cases in which the aetiology could not be determined were due to hereditary disease, as details of family history were not always available. Consanguinity is certainly common in South India ( $26 \%$ of marriages) but there is little available information from West Africa or Chile.

Autosomal dominant or X-linked disease accounted for $4(1.4 \%), 14(4.6 \%)$ and $18(18.3 \%)$ cases in each location. The discrepancy may be due to the availability of better medical records in Chile. Identification of these patients

Table VI. Preventive measures for blinding disorders of children

\begin{tabular}{|c|c|c|c|}
\hline Disorder & Primary prevention & $\begin{array}{l}\text { Secondary } \\
\text { prevention }\end{array}$ & $\begin{array}{l}\text { Tertiary } \\
\text { prevention }\end{array}$ \\
\hline $\begin{array}{l}\text { Corneal scarring from } \\
\text { VAD/measles/TEM/ } \\
\text { diarrhoea }\end{array}$ & $\begin{array}{l}\text { Promote breast feeding; nutrition education; } \\
\text { measles immunisation; vit. A prophylaxis; } \\
\text { health education }\end{array}$ & High-dose vitamin A & $\begin{array}{l}\text { Optical iridectomy/ } \\
\text { (keratoplasty) }\end{array}$ \\
\hline Ophthalmia neonatorum & $\begin{array}{l}\text { Health education; antenatal care; prophylaxis in } \\
\text { newborn }\end{array}$ & $\begin{array}{l}\text { Topical/systemic } \\
\text { antiobiotics }\end{array}$ & (Keratoplasty) \\
\hline Cataract & Rubella immunisation; genetic counselling & Early surgery & Late surgery \\
\hline Glaucoma & Rubella immunisation; genetic counselling & Early surgery & - \\
\hline ROP & Good neonatal care; ?surfactants & Cryotherapy/laser & - \\
\hline
\end{tabular}

ROP, retinopathy of prematurity; TEM, traditional eye medicines; VAD, vitamin A deficiency. 
and genetic counselling offers the possibility of reducing blindness from dominant and $\mathrm{X}$-linked hereditary disease.

\section{Control of Childhood Blindness}

The principles of prevention (primary, secondary and tertiary) provide a useful concept when considering prevention of blindness in children.

Strategies for primary, secondary and tertiary prevention to reduce childhood visual loss from various causes are given in Table VI.

Primary preventive measures, including measles immunisation, nutrition education and vitamin A supplementation, can be provided through child survival programmes. Secondary preventive measures require the early identification and treatment of neonates with congenital cataract, glaucoma, ROP and ophthalmia neonatorum, and the treatment of preschool children with xerophthalmia and corneal ulcer. The importance of each condition will vary from country to country.

Tertiary prevention (i.e. restoration of sight) is more problematic in children with early-onset disease because of amblyopia. Useful vision can usually be restored to a child blind from unoperated congenital cataracts, and early surgery and accurate correction of aphakia are likely to result in better visual rehabilitation. Occasionally either keratoplasty or optical iridectomy can restore some vision to a child blind from corneal scar.

\section{CONCLUSION}

These studies have used a standardised reporting form to document the different patterns of childhood severe visual impairment and blindness in three locations of the world.

A variety of control programmes are indicated in each location. Overall 50-70\% of childhood blindness in West Africa, South India and Chile could have been avoided if preventive screening and therapeutic services had been available and utilised.

These studies were supported by the Oxford Congress Award, the Cheltenham Ophthalmology Scholarship, Rotary International and Christoffel Blindenmission.

Key words: Childhood blindness.

\section{REFERENCES}

1. Foster A. Childhood blindness. Eye 1988;2(Suppl):S27-36.

2. Moriarty B. Childhood blindness in Jamaica. Br J Ophthalmol 1988;72:65-7.

3. Sauter J. Xerophthalmia and measles in Kenya. Groningen: Van Denderen, 1976.

4. Sauter J. Causes of blindness in 19 schools for the blind in Tanzania. Final report for Ministry of Health, Dar-es-Salaam, 1978.

5. Chirambo MC. Causes of blindness among students in blind school institutions in a developing country. Br J Ophthalmol 1976;60:655-68.

6. Sandford Smith J, Whittle HC. Corneal ulceration following measles in Nigerian children. Br J Ophthalmol 1979;63: $720-4$.

7. Olurin O. Aetiology of blindness in Nigerian children. Am J Ophthalmol 1970;70:533-40.

8. Gilbert C, Foster A, Thylefors B, Negrel DA. Childhood blindness: a new form for recording causes of visual loss in children. WHO Bulletin. (In press).

9. Foster A, Gilbert CE. Epidemiology of childhood blindness. Eye 1992;6:173-6.

10. Report of the World Health Organisation meeting on childhood blindness. Geneva: WHO/PBL 1990.90.19. Unpublished document.

11. Foster A, Sommer A. Corneal ulceration, measles, and childhood blindness in Tanzania. Br J Ophthalmol 1986;71: $331-43$.

12. CRYO-ROP Group. Multicentre trial of cryotherapy for retinopathy of prematurity. One year outcome: structure and function. Arch Ophthalmol 1990;108:1408-16. 